\title{
Recovery of valuable components from coal consumption waste
}

\author{
Tatiana Cherkasova ${ }^{1}$, Elizaveta Cherkasova $^{1}$, Anastasia Tikhomirova $^{1}$, Andrey \\ Golovachev ${ }^{1}$, and Andrey Papin ${ }^{1 *}$ \\ ${ }^{1}$ T.F. Gorbachev Kuzbass State Technical University, 650000, Russian Federation
}

\begin{abstract}
Today, more than $56 \%$ of all coal in Russia is mined in Kuzbass. As a result of its burning, about half a million ash and slag waste (ASW) is generated per year. Ash dumps with such waste are constantly dusting; mobile ions of inorganic substances are washed away by precipitation, polluting the environment. Burned coals, being natural sorbents, contain impurities of many valuable elements, including rareearth and precious metals, while their content in ash increases several times and can reach payable concentrations. Therefore, it is necessary to develop a technology for recovery of valuable components from ash and slag and using the remaining ash mass in construction and fertilizer industries. The efficiency of flotoextraction and chemical concentration methods for recovery of valuable components is assessed in the paper. The composition of the initial ash and slag samples and the resulting products of their processing were analyzed using infrared spectroscopic and optical emission methods.
\end{abstract}

\section{Introduction}

Coal reserves in comparison with the reserves of other energy carriers are quite high. For example, according to experts, at the current rate of use, explored coal reserves will last for 200 years (for comparison: oil - only 60). Undoubtedly, the most environmentally friendly fuel is not coal, but natural gas. Nevertheless, despite of wealth of natural gas reserves, gasification, even in large cities of the Russian Federation, remains wanting. In cold winters in some regions, coal is still the only available energy source.

Kuznetsk coal basin is one of the largest in the world. The total geological coal reserves here are estimated at 319 billion tons. Today, over $56 \%$ of all Russian coal, as well as about $80 \%$ of all coking coal, is mined in Kuzbass.

In Russia, coal is in demand in all constituent entities of the Russian Federation. Its consumption in the market is as follows:

- Supply of power plants - 55.1\%

- Coke production - $19.3 \%$

- Public utility consumers and population $-13.3 \%$

- The needs of metallurgy $-1.3 \%$

*Corresponding author: ctg.htnv@kuzstu.ru 
- JSC Russian Railways - 0.7\%

- The Ministry of Defense of the Russian Federation - $0.4 \%$

- Nuclear industry $-0.3 \%$

- Other needs (State Reserve, cement plants, Ministry of Internal Affairs of the Russian Federation, etc.) $-9.6 \%$.

At the same time, the Siberian Generating Company reports the generation of about half a million ash and slag waste (ASW) per year. Such waste is stored in special dumps and paid additionally by the coal processing company; in addition, the dumps occupy large areas of arable land. Ash dumps are constantly dusting; mobile ions of inorganic substances are washed away by precipitation, polluting the environment. The non-use of ash and slag waste is based on a clearly rooted notion of ash as unusable waste. The use of ash is limited due to its intense dust making, dirt and gas generation.

Ashes and slag waste is very often used in the production of various building materials, ceramics, for thermal waterproofing, as well as in road construction, where they can be used instead of sand and cement.

Dry fly ash from electrostatic precipitators is more widely used. But the use of such waste is, nevertheless, limited, and this is due, along with the presence in them of burning products and large parts, also with their toxicity.

At the same time, ash and slag waste can serve as a source of a number of metals and elements [1-3]. Burned coals, being natural sorbents, contain impurities of many valuable elements, including rare-earth and precious metals, while their content in ash increases several times and can reach payable concentrations [4, 5].

For the above reasons, the use of such waste is one of the most pressing problems. Therefore, it is necessary to develop a technology for their separation to obtain valuable components. This is possible by removal or recovery of harmful and valuable components from ash and using the remaining ash mass in the construction fertilizer industries.

In turn, rare and rare earth elements, which are especially common in the Kuznetsk coal, are in demand on the modern high-tech market.

According to geological studies, despite the fact that Russia owns at least $20 \%$ of the world's reserves of rare earth metals, there are big problems with their mining and, most importantly, production. The extraction of raw materials now accounts for only about $2 \%$ of the world amount, with only one Russian company - the Solikamsk Magnesium Plant engaged in it. This raw material is processed in the countries of the former USSR, from where the final product goes to world markets. That is, the Russian consumer does not receive the final product - metals that are in demand in industries such as aircraft, rocket science, electronics, so, paradoxically, it is necessary to buy them abroad.

Thus, the development of technology for the processing coal consumption waste, using them as raw materials for obtaining valuable components will make it possible to turn waste into revenues, that is, partially cover the need for rare metals, and also improve the environmental situation.

At the first stage of processing ash and slag materials, the method of leaching them with mineral acids is traditionally used. Sulfuric or nitric acids are most often used as reagents [6-15].

In order to increase the concentration of valuable components to recoverable rate, it is necessary to process the waste, considering it in the same quality as conventional mineral raw materials. For this purpose, the ion flotation method was used in this work, which is the best suited for the recovery of substances from solutions with a very low concentration of components (up to $10^{-8} \mathrm{~mol} / \mathrm{l}$ ). 


\section{Research methods}

Before developing a working technology for waste separation, it is necessary to conduct a comprehensive study to determine their composition and also to monitor the change in the content of valuable components at each stage of processing. In this work, we used IR spectroscopic analysis, as well as inductively coupled plasma optical emission spectrometry using an iCAP 6500 DUO spectrometer.

IR spectroscopic analysis was performed using an Agilent Cary 630 FTIR FTIR spectrometer in the range of $4000-650 \mathrm{~cm}^{-1}$.

The basic components of the ash are primarily silicon, aluminum, iron and alkaline-earth metal compounds. For concentrating rare-earth metal compounds, the primary task is to separate these very components.

For the experiment, $1 \mathrm{~kg}$ of coal ash was taken from the Kemerovo State District Power Plant and leached with $2.5 \mathrm{M}$ nitric acid. Leaching was carried out by heating to $60-70{ }^{\circ} \mathrm{C}$ and settling during the day. After 24 hours, a gel of orthosilicic acid and silicates formed, which was diluted and filtered by a white ribbon filter. The obtained extract was subjected to further processing, and the precipitate was sent to the "tailings".

The filtrate was neutralized with a $12 \%$ solution of ammonium hydroxide at $\mathrm{pH} 5$ until the precipitation of the brown precipitate of iron(III) hydroxide ceased. The $\mathrm{pH}$ during the process was strictly controlled to avoid the co-precipitation of REE hydroxides. After separation of the precipitate, the $\mathrm{pH}$ of the extract was adjusted to 8.5 with an ammonia solution to precipitate of REE and aluminum hydroxides.

Then, the precipitate formed was re-dissolved in a $0.5 \mathrm{M}$ solution of nitric acid and rareearth elements were re-precipitated with oxalic acid at $\mathrm{pH} 1$. When the $\mathrm{pH}$ of the solution increased to 8 , complete precipitation occurred, however, an alkali-earth metal oxalate precipitate and partially hydroxides of elements precipitated.

The resulting substances were dried in air and analyzed by IR spectroscopy.

Ion flotation was carried out by selective sodium tetra- and dodecyl sulfate foaming agents, which are efficient ionic surfactants; 2-ethylhexanol was used as an extractant. The experiment was carried out in the range of $\mathrm{pH} 7.5-8.5$; the ratio of organic and aqueous phases being from 1:20 to 1:60. As a result of the reaction, REEs are transported through the aqueous phase into the organic phase in the form of stable complex compounds.

The analysis of the collected foam products by the method of optical emission spectrometry with inductively coupled plasma was carried out in several stages.

A $0.1 \mathrm{~g}$ ash sample was selected by the quartering method. Polyvinyl alcohol (1:1 ratio) was used as a binding agent. Samples were quantitatively transferred to an agate mortar and rubbed there to a constant shade of color. Then, the resulting mixture was poured into a mold in which it was pressed into a compact sample under a pressure of $5 \mathrm{t} / \mathrm{cm}^{2}$. The resulting compacts were produced according to the same procedure as standard samples for spectrometer calibration.

The ash was dried to constant weight, and then placed in a volumetric tube, poured with aqua regia up to the graduation line of $50 \mathrm{ml}$. The resulting heterogeneous mixtures in hermetically sealed tubes were kept in a special acid digestion system Hotblock. The extraction was carried out for 8 hours at $95{ }^{\circ} \mathrm{C}$. In closed vessels, the pressure was increased. Then the vessels cooled to room temperature until the morning of the next working day. After this, the extract was separated from the precipitate quantitatively, as far as possible. Then the extract was diluted to the desired volume (under the regulated concentration of background components). The resulting solution was analyzed.

The resulting tablets were placed in an UP 266 MACRO laser sampling chamber, purged with argon, which was sent to the atomization torch of the spectrometer. 
Analytical lines of the determined elements were selected based on the fact if they are free from spectral and matrix interference.

\section{Key results}

The position of the intense stretching vibration bands in the IR spectrum of 1617 and 1321 $\mathrm{cm}^{-1}$ characterizes the $\mathrm{C}-\mathrm{O}$ bond of carbonyl groups, which proves the presence of a large amount of metal oxalates in the sample.

Wide fuzzy bands related to stretching vibrations of associated hydroxides are observed in the area of $3437-3197 \mathrm{~cm}^{-1}$. Bands 919, 724, $786 \mathrm{~cm}^{-1}$ characterize the deformation vibrations of $\mathrm{OH}$ groups.

Peaks characteristic of crystallization water in the spectra are not observed. The IR spectrum of the precipitate obtained after re-precipitation with oxalic acid is shown in Figure 1.

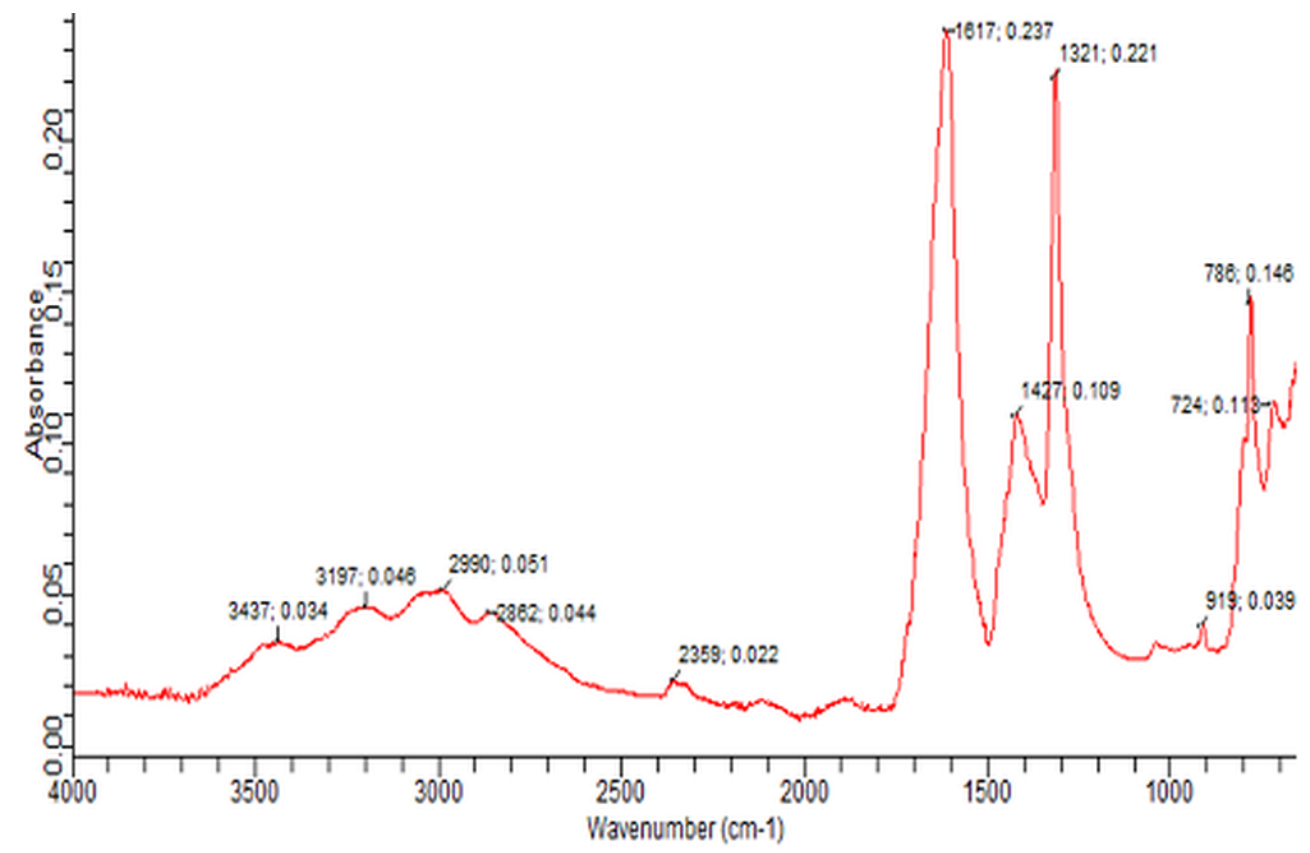

Fig. 1. IR spectrum of the precipitate obtained after re-precipitation with oxalic acid

When carrying out the flotoextraction process, a suspension of $500 \mathrm{~g}$ of ash and 21 of water was first prepared, $33 \mathrm{ml}$ of 2-ethylhexanol was added to it (to comply with the ratio of organic and aqueous phases of 1:60, respectively) and $27.11 \mathrm{~g}$ of tetradecyl sulfate.

The process was carried out on a FL-240 flotation machine for 5, 10, 15 minutes. The result is a stable gray foam with ash particles on the surface of the liquid. 
Table 1. The content of rare, trace and rare-earth elements in the ash of Kemerovo state district power station

\begin{tabular}{|c|c|c|}
\hline \multirow{2}{*}{ Elements } & \multicolumn{2}{|c|}{ Content } \\
\cline { 2 - 3 } & $\mathbf{\%}$ & $\mathbf{g} / \mathbf{t}$ \\
\hline $\mathrm{Sr}$ & $1,4 \cdot 10^{-2}$ & 140,00 \\
\hline $\mathrm{Ga}$ & $9,2 \cdot 10^{-4}$ & 9,20 \\
\hline $\mathrm{Zr}$ & $2,5 \cdot 10^{-4}$ & 2,50 \\
\hline $\mathrm{Nb}$ & $7,1 \cdot 10^{-4}$ & 7,10 \\
\hline $\mathrm{Mo}$ & $8,9 \cdot 10^{-4}$ & 8,90 \\
\hline $\mathrm{Au}$ & $1,2 \cdot 10^{-4}$ & 1,20 \\
\hline $\mathrm{V}$ & $5,5 \cdot 10^{-3}$ & 55,00 \\
\hline $\mathrm{P} 3 \ni:$ & $1,6 \cdot 10^{-3}$ & 16,00 \\
\hline $\mathrm{Y}$ & $6,7 \cdot 10^{-5}$ & 0,67 \\
\hline $\mathrm{Eu}$ & $2,1 \cdot 10^{-3}$ & 21,00 \\
\hline $\mathrm{La}$ & $7,2 \cdot 10^{-4}$ & 7,20 \\
\hline $\mathrm{Pr}$ & $1,7 \cdot 10^{-4}$ & 17,00 \\
\hline $\mathrm{Sm}$ & & \\
\hline
\end{tabular}

During the experiment, it was found that a large amount of 2-ethylhexanol is unsuitable for the process, since with the same ratios of the initial components, but with a decrease in the ratio of the aqueous and organic phases to 1:20, a white mass is formed instead of foam in the flotation process, which does not dry out in air at room temperature for a week. In this case, a viscous film forms on the surface of the flotation products, which prevents the evaporation of the liquid. When this mass is calcined at a temperature of $1000^{\circ} \mathrm{C}$, almost no dry residue is formed.

When the experiment was repeated, flotoextraction was carried out in 2 stages. To $500 \mathrm{~g}$ of ash, 21 of water and $33 \mathrm{ml}$ of 2-ethylhexanol were added, the weight of sodium tetradecyl sulfate was increased to $30.34 \mathrm{~g}$. After the first flotation, a gray film formed with extracted particles of ash components, and in the second stage the film practically did not form, that is, tetradecyl sulfate as a reagent-collector is quite efficient.

After replacing sodium tetradecyl sulfate with its homolog dodecyl sulfate, the following experiment was carried out:

$52 \mathrm{ml}$ of 2-ethylhexanol (ratio of aqueous and organic phases 1:40) and $2.00 \mathrm{~g}$ of sodium dodecyl sulfate were added to the same amount of ash and water as in the previous experiment. The mixture was floated for 5 and 10 minutes. As a result, a relatively small amount of foam products was formed, however, with prolonged sedimentation of the suspension, a stable foam formed, which was collected, dried in air, and calcined at a temperature of $1000{ }^{\circ} \mathrm{C}$ for two hours.

The results of studies of the obtained substances are presented in Table 2. 
Table 2. The assay of rare, trace and rare-earth elements of concentrate

\begin{tabular}{|c|c|}
\hline Element & Assay of concentrate, $\mathbf{\%} / \mathbf{g} / \mathbf{t}$ \\
\hline $\mathrm{Sr}$ & $1,4 \cdot 10^{-1} / 1400$ \\
\hline $\mathrm{Ga}$ & $4,9 \cdot 10^{-3} / 49$ \\
\hline $\mathrm{Zr}$ & $1,5 \cdot 10^{-1} / 1500$ \\
\hline $\mathrm{Nb}$ & $8,7 \cdot 10^{-3} / 87$ \\
\hline $\mathrm{V}$ & $3,3 \cdot 10^{-1} / 3300$ \\
\hline $\mathrm{Mo}$ & $2,1 \cdot 10^{-2} / 210$ \\
\hline$\Sigma \mathrm{P} 3 Э$ & $7,8 \cdot 10^{-2} / 780$ \\
\hline
\end{tabular}

\section{Conclusions}

Thus, it was found that the technology of nitric acid leaching with stepwise precipitation of iron(III) hydroxide and rare earth metals in the form of oxalates or hydroxides is feasible in view of the fact that it does not require expensive equipment and reagents. But it will only work more efficiently when applied to ash and slag waste with a high assay of rare earth elements in the samples.

To increase the concentration of these elements in the ash, it should initially be processed. And the best option for this is flotoextraction method [16-18].

The analysis showed that dodecyl sulfate is a more efficient foaming agent-collector, since the highest concentration of rare earth elements in foam products is formed when it is used. In addition, it is consumed in smaller quantities during recovery.

\section{References}

1. O.S. Danilov, A.V. Belov, I.V. Grebenyuk, Mining Informational and Analytical Bulletin, 7, 16 (2018)

2. P. Deutz, H. Baxter, D. Gibbs, W.M. Mayers, H.I. Gomes, Geoforum, 85, 336 (2017)

3. D. Bradio, W. Zukowski, P. Czupryński, K. Witkowski, Inzynieria Mineralna, 16:1, 163 (2015)

4. Z. Ma, S. Zhang, H. Zhang, F. Cheng, J. of Cleaner Production, 230, 302 (2019).

5. W. Urbańczyk, M. Lutyński, IOP Conference Series: Materials Science and Engeneering, 641:1, 155425 (2019)

6. A Kumari, R Parween, S Chakravarty, K. Parmar, D.D. Pathak, J.-C. Lee, M.K. Jha, Hydrometallurgy, 187, 1 (2019)

7. V. Balaram, Geoscience Frontiers, 10:4, 1285 (2019)

8. P. Liu, R. Huang, Y. Tang, Environmental Science and Technology, 53:9, 5369 (2019)

9. Z. Wang, S. Dai, J. Zou, D. French, I.T. Graham, International J. of Coal Geology, 203, 1 (2019)

10. M. Tang, C. Zhou, N. Zhang, J. Pan, S, Cao, T. Hu, W. Ji, Z. Wen, T. Nie, International J. of Coal Preparation and Utilization, (to be published).

11. C. Lanzerstorfer, Energy Reports, 4, 660 (2018)

12. S. Das, G. Gaustad, A. Sekar, E. Williams J. of Cleaner Production, 189, 539 (2018). 
13. P.K. Sahoo, K. Kim, M.A. Powell, S.M. Equeenuddin. International J. of Coal Science and Technology, 3:3, 267 (2016)

14. R.K. Taggart, J.C. Hower, G.S. Dwyer, H. Hsu-Kim, Environmental Science and Technology, 50:11, 5919 (2016)

16. V.I. Kuz'min, V.N, Kuz'mina, P.N. Kuznetsov, S.M. Kolesnikova, Solid Fuel Chemistry, 50:2, 120 (2016)

17. B.S. Ksenofontov, A.S. Kozodaev, R.A. Taranov, Ecology and Industry of Russia, V. 20:4, 12 (2016)

18. R.C. Smith, R.K. Taggart, J.C. Hower, M.R. Wiesner, H. Hsu-Kim, Environmental Science and Technology, 53:8, 4490 (2019)

19. L. Chang, Y. Cao, G. Fan, C. Li, W. Peng, RSC Advances, 9:35, 20226-20239 (2019) 